\title{
Speed Control for a PMSM Servo System Using Model Reference Adaptive Control and an Extended State Observer
}

\author{
Xiaodi $\mathrm{Li}^{*}$ and Shihua $\mathrm{Li}^{\dagger}$ \\ "Key laboratory of Measurement and Control of Complex Systems of Engineering, \\ Ministry of Education, Nanjing, China \\ ${ }^{\dagger}$ School of Automation, Southeast University, Nanjing, China
}

\begin{abstract}
In this paper, the speed regulation problem of permanent synchronous motor (PMSM) systems under the vector control framework is studied. A model reference adaptive controller (MRAC) based on the Lyapunov stability theory is first designed. Since the standard MRAC method provides poor disturbance rejection performance in the case of strong disturbances, a composite control method which combines the MRAC method and the disturbance estimation method, called the MRAC+ESO method, is proposed. An extended state observer (ESO) is introduced to estimate the lumped disturbances. The obtained estimated value acts as a feedforward compensation term to the MRAC controller. A stability analysis of the composite control method is given. Simulation and experimental results are presented and compared to show the effectiveness of the proposed control method.
\end{abstract}

Key words: Extended state observer (ESO), Model reference adaptive control (MRAC), Permanent magnet synchronous motor (PMSM), Speed regulation system

\section{INTRODUCTION}

The permanent magnet synchronous motor (PMSM) has been widely used in motion control applications due to its excellent features such as a simple structure, high efficiency, high power density and user-friendly maintenance. Many of the industrial applications for servo systems require high performance such as fast response, low overshoot, and insensitivity to disturbances and parameter variations. However, the PMSM is nonlinear plant with states coupling. Although there are methods to make the states decoupled approximately such as setting the referenced direct axis current to zero, it is still difficult for the conventional linear control methods, including the proportional-integral (PI), to achieve a high-precision performance [1]. To enhance the control performance, more advanced control methods have been introduced to PMSM servo systems, e.g., adaptive control [2]-[6], [19], disturbance estimation based control [7], [8],

Manuscript received Oct. 19, 2013; accepted Jan. 29, 2014.

Recommended for publication by Associate Editor Dong-Hee Lee.

${ }^{\dagger}$ Corresponding Author: 1sh@seu.edu.cn

Tel: +86-25-83793785, Southeast University

Key laboratory of Measurement and Control of Complex Systems of Engineering, Ministry of Education, China sliding model control [9]-[11], finite-time control [17], predictive control [13], [14], fuzzy control [15], [18], [19], neural network control [1], [12], [15], [16], etc. These methods have improved the performance of PMSM servo systems from different aspects.

Among these methods, the adaptive control method has been widely used in the situations where the system parameters are inaccurately known or the system is operated over a wide range of operating conditions. In such situations, the usual controller with fixed gains may not provide a satisfactory performance. One such concept is the direct adaptive control which identifies the parameters of unknown systems and uses the current parameter to synthesize suitable control gains. This approach is easy to understand and implement, but it needs to identify the system parameters online which may not be allowed in some situations. For example, in many application cases, the PMSM system may not be allowed to add a sufficiently exciting periodical input signal for the online inertia identification [3].

Another concept is the model reference adaptive control (MRAC) approach. It employs a reference model to generate a reference output. The adaptive laws, derived by means of the Lyapunov stability theory, modify the parameters of the controller without the necessity of a sufficiently exciting 
system input signal [21]. There have been some promising research reports on the application of the MRAC method to motion control systems. In [22], the MRAC technique is employed for the velocity and currents loops of induction motor control systems. In [24], the MRAC method is applied to the outer speed loop of a permanent magnet brushless DC motor. In [23], a MRAC algorithm for the robust control of a PMSM is proposed and applied to the three control loops including a speed loop and two current loops. [25] and [27] combine the MRAC method and the fuzzy control method. The MRAC method and the variable structure control method in the speed loop improve the performance of the DC motor system and the induction motor system, respectively.

In industrial situations, PMSM systems always encouter different disturbances, e.g., friction force, load disturbances and unmodeled dynamics [29]. The conventional control methods may not react directly and quickly to reject these disturbances, but these control methods can finally suppress them through feedback regulation [3]. Although the disturbances can usually not be measured, there is still one efficient way to quickly reject disturbances. This can be done by estimating the disturbances and feedforward compensating them based on their estimated. Disturbance estimation based control is one of the most useful methods and it has been well used in different applications such as, robotic systems [36], spacecraft systems [35], PMSM systems [28], general motion control systems [37], etc. The extended state observer (ESO) technique is one of the most useful observers in the disturbance observer field. Under this framework, many control methods based on the feedforward compensation techniques for disturbances have been developed for PMSM systems [28], [29].

In this paper, the speed regulation problem for PMSM systems is studied. The target here is to pursue a high closed loop performance with good adaptation ability for different working conditions as well as strong robustness against disturbances and uncertainties. First, a MRAC method is developed for the speed loop of the PMSM system. Second, to improve the disturbance rejection ability, a composite speed control method using the MRAC method and disturbance estimation based on the compensation technique is proposed for PMSM servo systems. The simulation and experimental comparison results of both methods are also presented.

This paper is organized as follows. Section II introduces the PMSM model. The MRAC-based speed control scheme is proposed in Section III. Section IV shows the MRAC+ESO composite control strategy. Some conclusions are given in Section V.

\section{The MAthematicAl Model OF THE PMSM}

The model of the surface mounted permanent magnet synchronous motor is expressed as follows [30]:

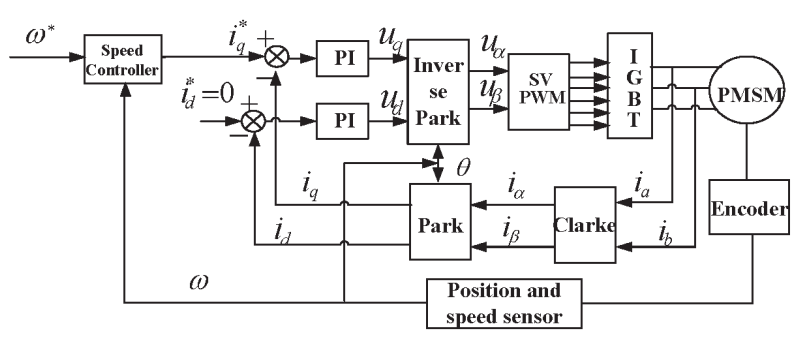

Fig. 1. The block diagram of the PMSM control system.

$$
\left(\begin{array}{l}
\dot{i}_{d} \\
\dot{i}_{q} \\
\dot{\omega}
\end{array}\right)=\left(\begin{array}{ccc}
-\frac{R_{s}}{L} & n_{p} \omega & 0 \\
-n_{p} \omega & -\frac{R_{s}}{L} & -\frac{n_{p} \psi_{f}}{L} \\
0 & \frac{K_{t}}{J} & -\frac{B}{J}
\end{array}\right)\left(\begin{array}{c}
i_{d} \\
i_{q} \\
\omega
\end{array}\right)+\left(\begin{array}{c}
\frac{u_{d}}{L} \\
\frac{u_{q}}{L} \\
-\frac{T_{L}}{J}
\end{array}\right)
$$

where $R_{s}$ is the stator resistance. $i_{d}$ and $i_{q}$ are the $d$ and $q$ axes stator currents. $u_{d}$ and $u_{q}$ are the $d$ and $q$ axes stator voltages. $n_{p}$ is the pole pairs number. $L$ is the stator inductance. $\omega$ is the rotor angular velocity. $\psi_{f}$ is the flux linkage. $K_{t}$ is the torque constant. $J$ is the rotor inertia. $B$ is the viscous friction coefficient, and $T_{L}$ is the load torque.

The design procedure is based on the framework of the vector control, where the structure of the cascade control loops, including a speed tracking loop and two current tracking loops, are employed. Here two PI controllers are adopted in the two current loops. As shown in Fig. 1, the rotor angular velocity can be obtained from the position sensor. The currents $i_{d}$ and $i_{q}$ can be calculated from $i_{\alpha}$ and $i_{\beta}$ by the Clarke and Park transformation. Usually, the reference current is set as $i_{d}{ }^{*}=0$. The reference current $i_{q}{ }^{*}$ is determined by the speed loop controller. This paper concentrates on the design of the speed loop controller.

From (1), the torque equation of the PMSM system can be written as:

$$
\begin{aligned}
\dot{\omega} & =\frac{K_{t}}{J} i_{q}-\frac{B \omega}{J}-\frac{T_{L}}{J} \\
& =\frac{K_{t}}{J} i_{q}^{*}-\frac{B \omega}{J}-\frac{T_{L}}{J}-\frac{K_{t}}{J}\left(i_{q}^{*}-i_{q}\right) \\
& =-\frac{B \omega}{J}+\frac{K_{t}}{J} i_{q}^{*}+d(t) \\
& =-a \omega+b i_{q}^{*}+d(t)
\end{aligned}
$$

where $a=\frac{B}{J}$ and $b=\frac{K_{t}}{J} \cdot d(t)=-\frac{T_{L}}{J}-\frac{K_{t}}{J}\left(i_{q}^{*}-i_{q}\right)$ can be considered as the lumped disturbances including the load torque disturbance and the tracking error of the $q$ axis 


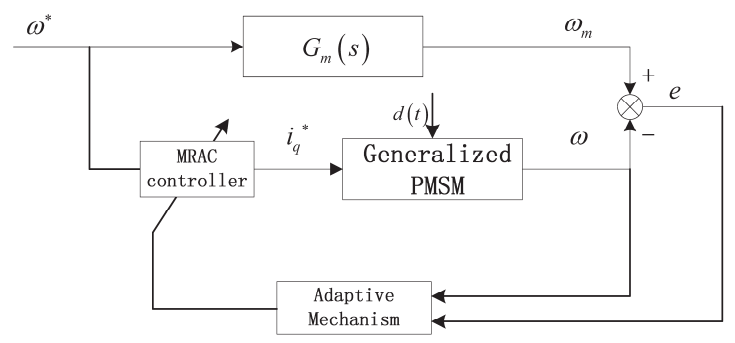

Fig. 2. The block diagram of the standard MRAC method for the PMSM system.

current loop. Based on the model shown in (2), a speed loop controller is designed to improve the adaptation and disturbance rejection ability of the PMSM speed system.

\section{MRAC CONTROLLER DESIGN FOR THE PMSM}

\section{A. Control Design}

The MRAC structure is shown in Fig. 2, where $G_{m}(s)$ is the reference model, and $\omega^{*}$ is the reference speed. In Fig. 2, the "Generalized PMSM" represents the two current loops that include the PMSM and other components [3].

The reference model is chosen as:

$$
\dot{\omega}_{m}=-a_{m} \omega_{m}+b_{m} \omega^{*}
$$

where $a_{m}>0$ and $b_{m}>0$ are parameters for this reference model.

Suppose the control law is described as:

$$
i_{q}^{*}=h(t) \omega+k(t) \omega^{*}
$$

where $k(t)$ is the variable feedforward gain and $h(t)$ is the variable feedback gain.

Substituting (4) into (2), yields:

$$
\dot{\omega}=-(a-b h(t)) \omega+b k(t) \omega^{*}
$$

Here, define the speed tracking error and the parameter error as follows:

$$
\begin{gathered}
e=\omega_{m}-\omega \\
\phi=\left[\begin{array}{l}
k^{*}-k(t) \\
h^{*}-h(t)
\end{array}\right]
\end{gathered}
$$

where $k^{*}=\frac{b_{m}}{b}$ and $h^{*}=\frac{a-a_{m}}{b}$.

Then, differentiating (6) along system (3) and (5) yields:

$$
\begin{aligned}
\dot{e} & =-a_{m} \omega_{m}+b_{m} \omega^{*}+a \omega-b h(t) \omega-b k(t) \omega \\
& =-a_{m} e+b \phi^{T}\left[\omega^{*} \omega\right]^{T}
\end{aligned}
$$

Considering the Lyapunov function:

$$
V=\frac{1}{2} e^{2}+\frac{b}{2} \phi^{T}\left[\begin{array}{ll}
\gamma_{1} & \\
& \gamma_{2}
\end{array}\right] \phi
$$

TABLE I

THE PARAMETERS OF THE PMSM

\begin{tabular}{lc}
\hline & Type: EMJ08ADB11 \\
\hline Rated power $P_{N}$ & $750 \mathrm{~W}$ \\
Stator inductance $L$ & $0.004 \mathrm{H}$ \\
Rated voltage $U_{N}$ & $200 \mathrm{~V}$ \\
Number of Pole pairs $n_{p}$ & 4 \\
Rated current $I_{N}$ & $4.71 \mathrm{~A}$ \\
Stator resistance $R_{s}$ & $1.74 \Omega$ \\
Rated speed $n_{N}$ & $3000 \mathrm{r} / \mathrm{min}$ \\
Rotor flux $\psi$ & $0.402 \mathrm{~Wb}$ \\
PMSM inertia $J$ & $1.78 \times 10^{-4} \mathrm{Kg} \cdot \mathrm{m}^{2}$ \\
Viscous coefficient $B$ & $7.4 \times 10^{-5} \mathrm{~N} \cdot \mathrm{m} \cdot \mathrm{s} / \mathrm{rad}$ \\
\hline
\end{tabular}

where $\gamma_{1}>0$ and $\gamma_{2}>0$.

The differentiation of (9) along the trajectory of (8) yields:

$$
\begin{aligned}
\dot{V} & =e \dot{e}+b \phi^{T}\left[\begin{array}{ll}
\gamma_{1} & \\
& \gamma_{2}
\end{array}\right] \dot{\phi} \\
& =-a_{m} e^{2}+b e \phi^{T}\left[\begin{array}{c}
\omega^{*} \\
\omega
\end{array}\right]-b \phi^{T}\left[\begin{array}{ll}
\gamma_{1} & \\
& \gamma_{2}
\end{array}\right]\left[\begin{array}{l}
\dot{k}(t) \\
\dot{h}(t)
\end{array}\right]
\end{aligned}
$$

Choose:

$$
\left[\begin{array}{l}
\dot{k}(t) \\
\dot{h}(t)
\end{array}\right]=\left[\begin{array}{ll}
\frac{1}{\gamma_{1}} & \\
& \frac{1}{\gamma_{2}}
\end{array}\right]\left(e\left[\begin{array}{c}
\omega^{*} \\
\omega
\end{array}\right]+\left[\begin{array}{l}
k^{*}-k(t) \\
h^{*}-h(t)
\end{array}\right]\right)
$$

Then it can be obtained that:

$$
\dot{V}=-a_{m} e^{2}-b \phi^{T} \phi=-a_{m} e^{2}-b\|\phi\|^{2} \leq 0
$$

Therefore, according to the Lyapunov stability theorem, it can be concluded that the closed loop system is asymptotically stable.

\section{B. Simulation and Experimental Results}

To demonstrate the efficiency of the MRAC method, some simulation and experiments on a PMSM servo system have been carried out. Both the MRAC and the PI methods are tested on the PMSM system.

The tested motor in the simulation and experiments is a 750W PMSM designed for servo applications. The PMSM parameters are listed in Table I: stator resistance $R_{s}=1.74 \Omega$, stator inductances $L_{d}=L_{q}=L=0.004 \mathrm{H}$, number of pole pairs $n_{p}=4$, moment of inertia $J=1.78 \times 10^{-4} \mathrm{Kg} \cdot \mathrm{m}^{2}$, viscous coefficient $B=7.4 \times 10^{-5} \mathrm{~N} \cdot \mathrm{m} \cdot \mathrm{s} / \mathrm{rad}$, rotor flux 


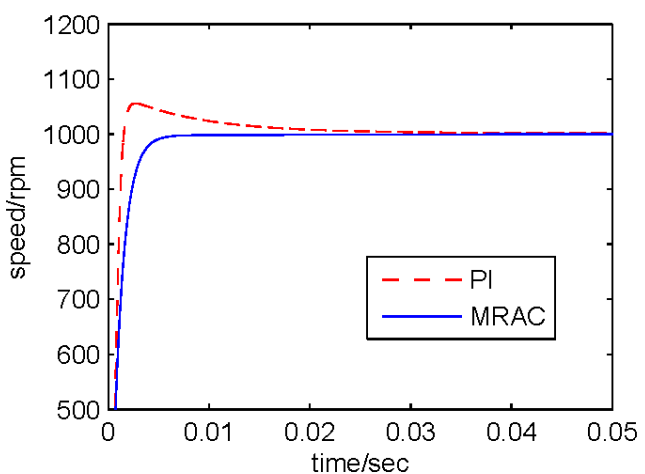

(a)

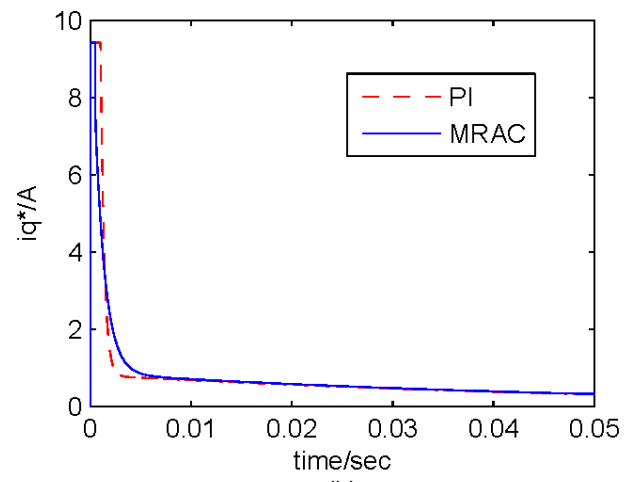

(b)

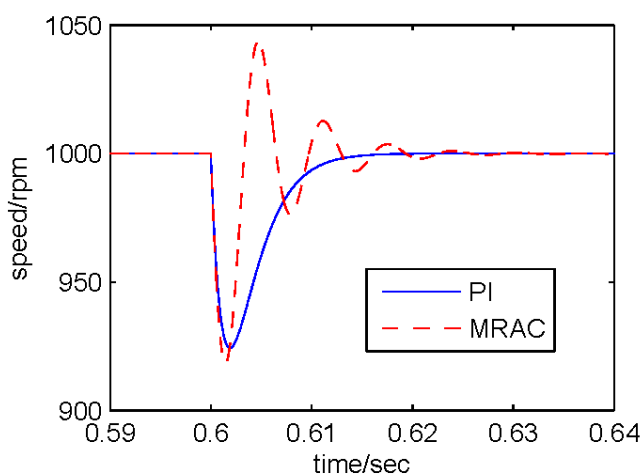

(c)

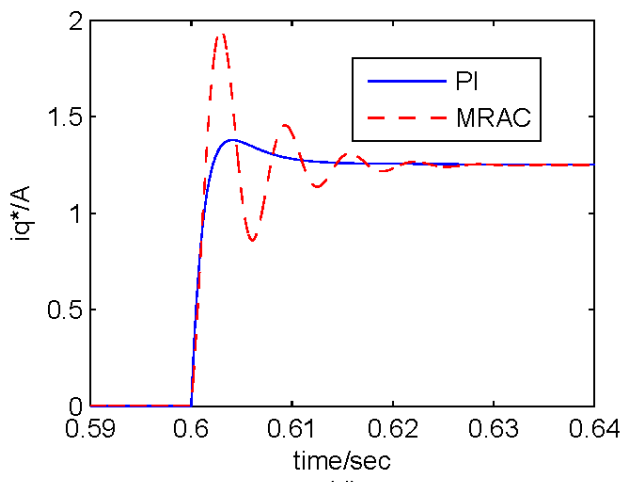

(d)

Fig. 3. Simulation response curves under the MRAC and the PI controllers: (a) speed. (b) $i_{q}^{*}$. (c) speed response curves in the presence of a load torque disturbance. (d) $i_{q}^{*}$ response curves in the presence of a load torque disturbance.

$\psi_{f}=0.402 \mathrm{~Wb}$. The PI parameters of both current loops are: $K_{p}=42$ and $K_{i}=2600$. The saturation limit of the $q$-axis reference current is $\pm 9.42 \mathrm{~A}$.

Simulation Results: The parameters for the PI speed controller are: $K_{p}=0.2$ and $K_{i}=40$. For the MRAC speed controller they are: $a_{m}=b_{m}=100$ and $\gamma_{1}=\gamma_{2}=0.015$. Fig. 3(a) and (b) show the response curves of the MRAC-based controller and the PI controller in the case of a $1000 \mathrm{rpm}$ reference speed. In the simulation, a load torque $T_{L}=2 \mathrm{~N} \cdot \mathrm{m}$ is applied at $t=0.6 \mathrm{~s}$. The speed and $i_{q}{ }^{*}$ response curves are also given in Fig. 3 (c) and (d).

Experimental Results: To evaluate the performance of the MRAC method, an experimental setup system for the speed control of a PMSM has been built. The configuration of the experimental setup and the experimental test setup itself are shown in Fig. 4 and Fig. 5. All of the speed control algorithms including the SVPWM are implemented by a TMS320F2808 DSP with a clock frequency of $100 \mathrm{MHz}$. The control algorithm is implemented using C-program. The speed-loop and current-loop sampling periods are $250 \mu \mathrm{s}$

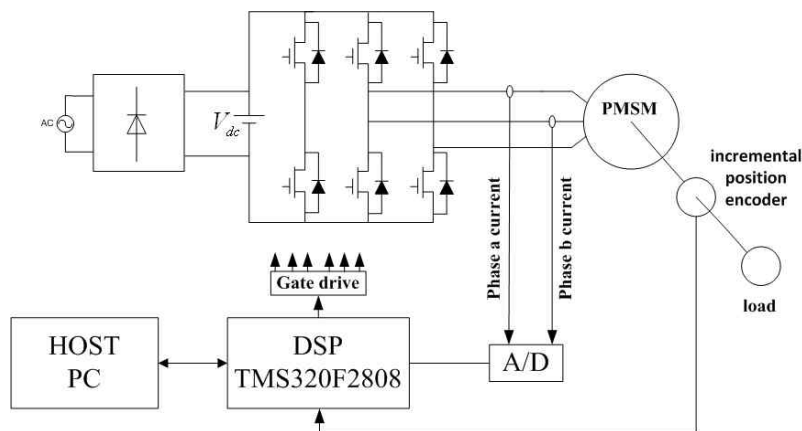

Fig. 4. The configuration of the experimental system.

and $60 \mu \mathrm{s}$, respectively. The PMSM is driven by a three-phase pulse width modulation (PWM) inverter with an intelligent power module (IPM) with a switching frequency of $10 \mathrm{kHz}$. The phase currents are measured by Hall-effect devices and are converted through two 12-bit analog to digital converters. An incremental position encoder of 2500 lines is used to measure the rotor speed and the absolute rotor position.

The parameters of the speed-loop controller are selected as: $a_{m}=b_{m}=100$ and $\gamma_{1}=\gamma_{2}=1$. Some experimental results are shown in Figs. 6, 7 and 8 when the reference speed is 


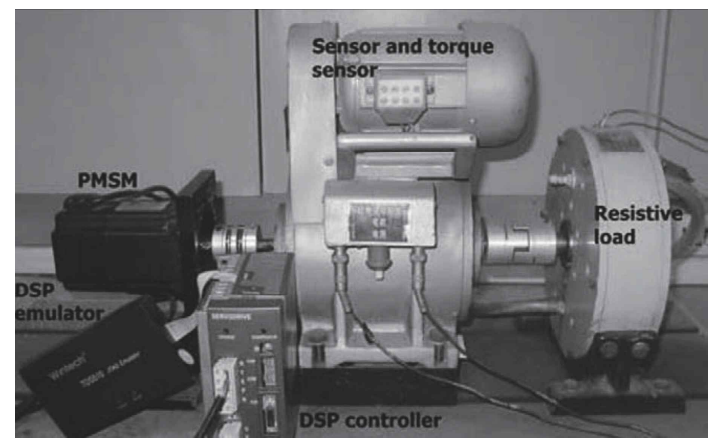

Fig. 5. The experimental test setup.

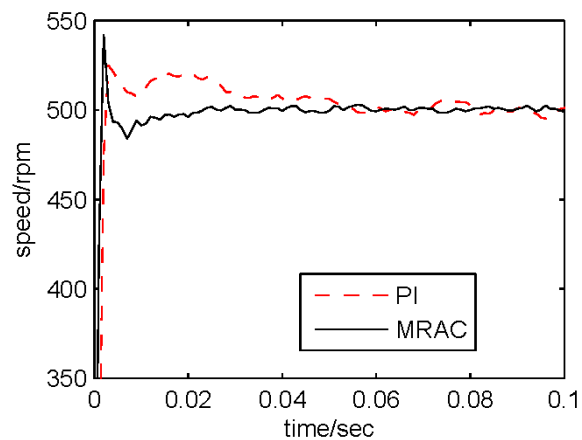

(a)

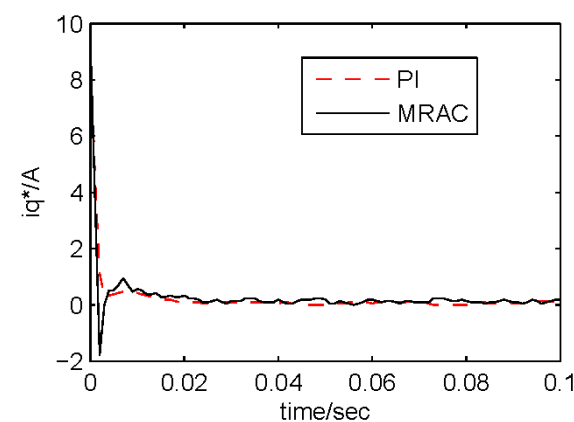

(b)

Fig. 6. Experimental response curves when the reference speed is $500 \mathrm{rpm}$ : (a) speed and (b) $i_{q}{ }^{*}$

given as $500 \mathrm{rpm}, 1000 \mathrm{rpm}$ and $2000 \mathrm{rpm}$, respectively. When compared with the PI controller, it seems that the MRAC-based controller does not have much of an advantage. Then the rotor inertia $J$ is increased to $11 J$. Experimental tests have also been carried out to evaluate the performance of the two control methods working in this situation. The results are shown in Figs. 9, 10 and 11. From these results, it can be seen that the performance of the controller with fixed gains (PI) becomes worse when the inertia of the system is changed. However, the MRAC controller with variable gains can adapt to the situation and get a high performance.

Tests also have been carried out to evaluate the performance in the presence of sudden load torque disturbances. When the PMSM system is running at a steady speed, a load torque $T_{L}$ is added suddenly and removed after

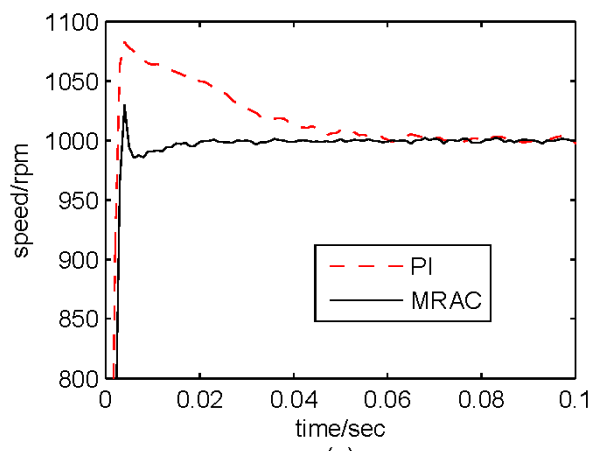

(a)

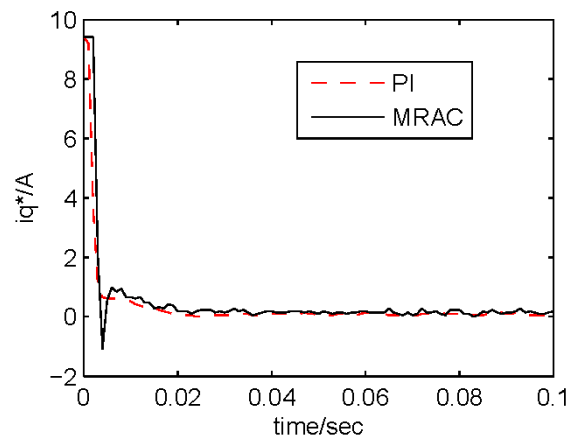

(b)

Fig. 7. Experimental response curves when the reference speed is $1000 \mathrm{rpm}$ : (a) speed and (b) $i_{q}^{*}$

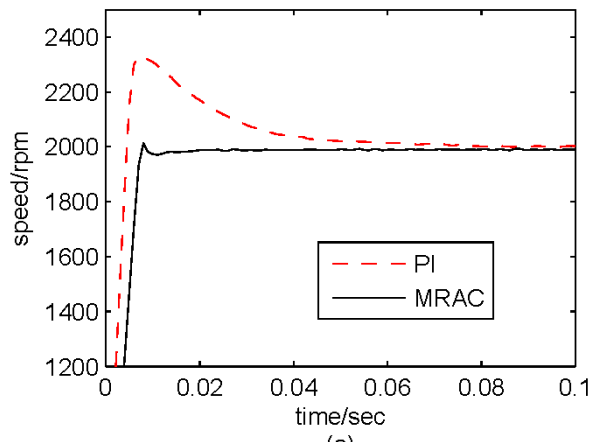

(a)

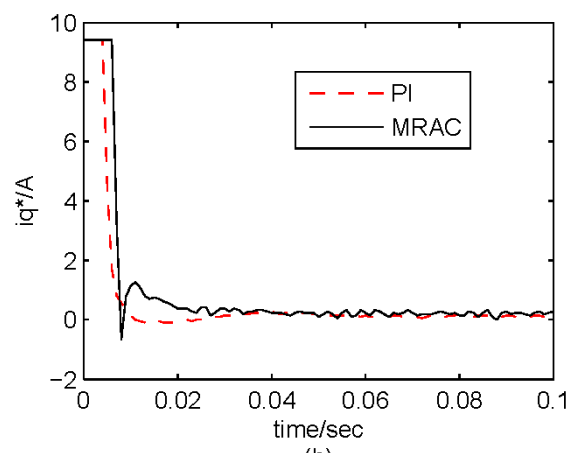

(b)

Fig. 8. Experimental response curves when the reference speed is $2000 \mathrm{rpm}$ : (a) speed and (b) $i_{q}{ }^{*}$

some duration. The experimental results are given in Figs. 12, 13 and 14. It can be seen that the MRAC method shows a 


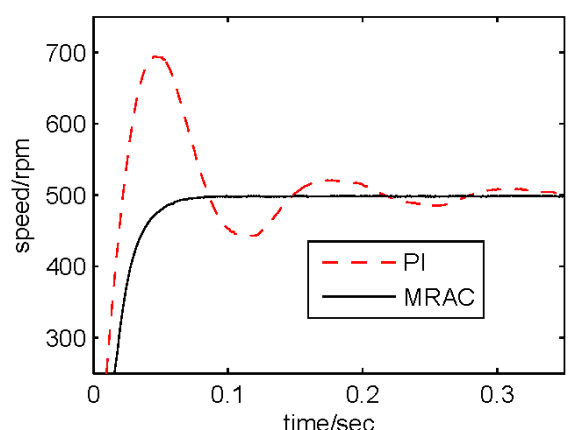

(a)

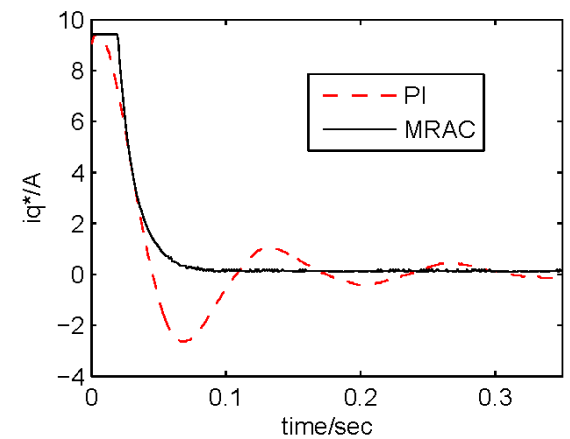

(b)

Fig. 9. Experimental response curves when $J$ is increased to $11 \mathrm{~J}$ and the reference speed is $500 \mathrm{rpm}$ : (a) speed and (b) $i_{q}^{*}$

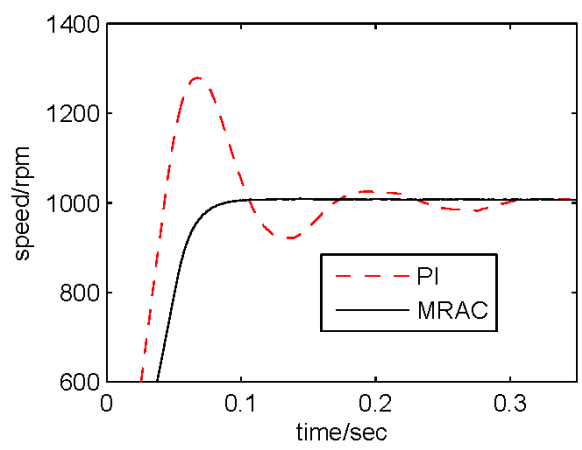

(a)

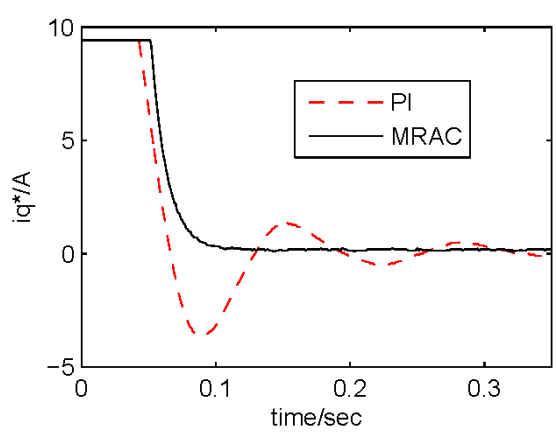

(b)

Fig. 10. Experimental response curves when $J$ is increased to $11 \mathrm{~J}$ and the reference speed is $1000 \mathrm{rpm}$ : (a) speed and (b) $i_{q}{ }^{*}$

poor disturbance rejection ability which may limit its application. In the following section, a composite method will be proposed to improve the disturbance rejection ability of

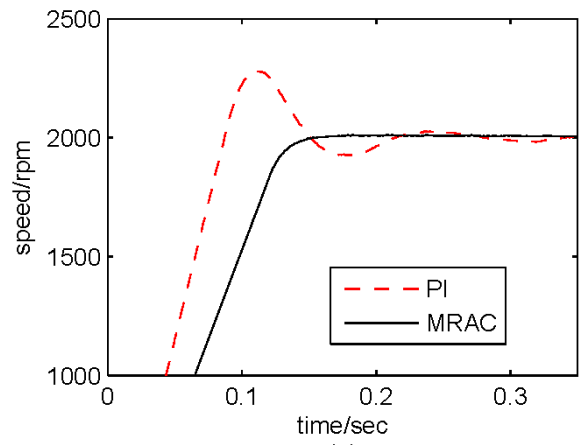

(a)

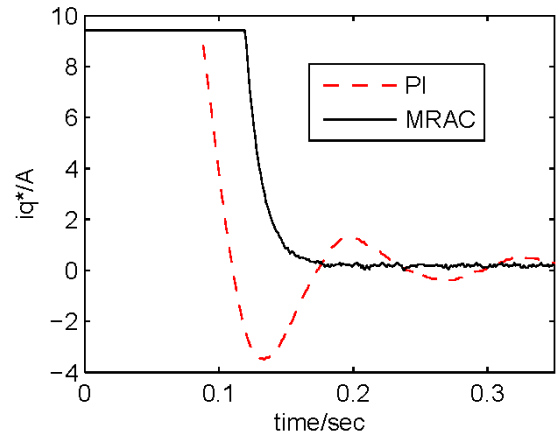

(b)

Fig. 11. Experimental response curves when $J$ is increased to $11 \mathrm{~J}$ and the reference speed is $2000 \mathrm{rpm}$ : (a) speed and (b) $i_{q}{ }^{*}$

the closed loop system using the disturbance estimation theory.

\section{MRAC+ESO COMPOSITE CONTROLLER DESIGN FOR THE PMSM}

\section{A. Control Design}

In the design procedure presented above, the influence of the disturbance $d(t)$ is ignored. In fact, the load torque disturbances and un-modeled dynamics are unavoidable in real industrial situations. These disturbances may degrade the performance of the system. For the speed loop of the PMSM system, the lumped disturbances here include the load torque disturbances and the tracking error of the $q$ axis current loop.

If the lumped disturbances are estimated and feed-forward based on the observed value, the influence caused by the disturbance $d(t)$ will be restrained. In this paper, an ESO is added to the MRAC controller. It regards the disturbances $d(t)$ as a new state of the system and estimates both the states and the disturbances. The detail principle of the ESO can be found in [31]-[32].

According to (2), define $x_{1}=\omega$ and $x_{2}=d(t)$, then (2) can be written as: 


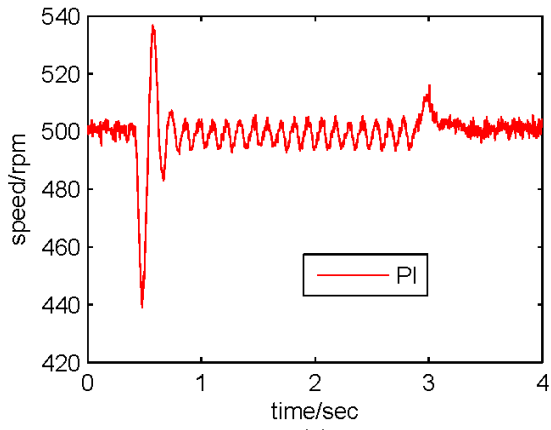

(a)

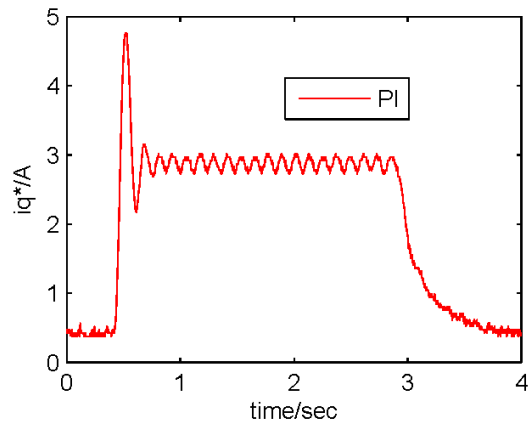

(b)

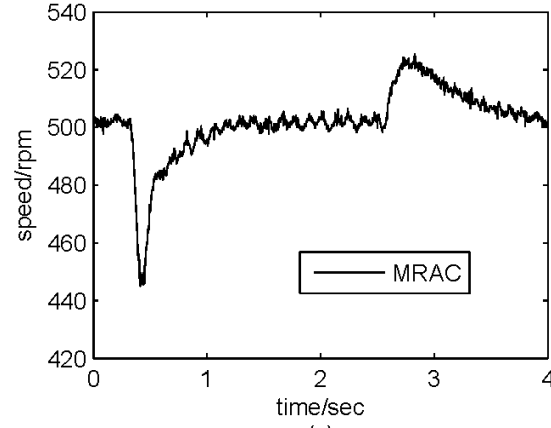

(c)

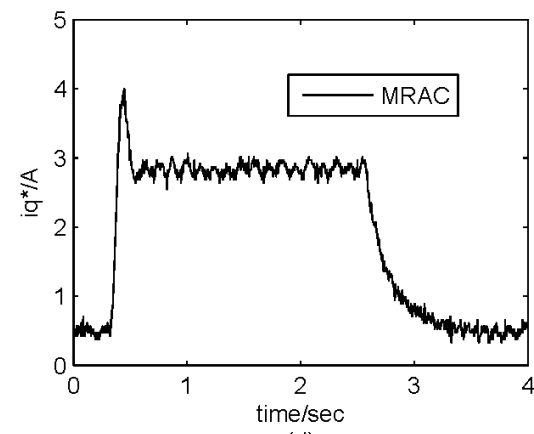

Fig. 12. Experimental response curves in the presence of a sudden load torque disturbance in the case of $500 \mathrm{rpm}$ : (a) speed (PI). (b) $i_{q}^{*}$ (PI). (c) speed (MRAC). (d) $i_{q}^{*}$ (MRAC).

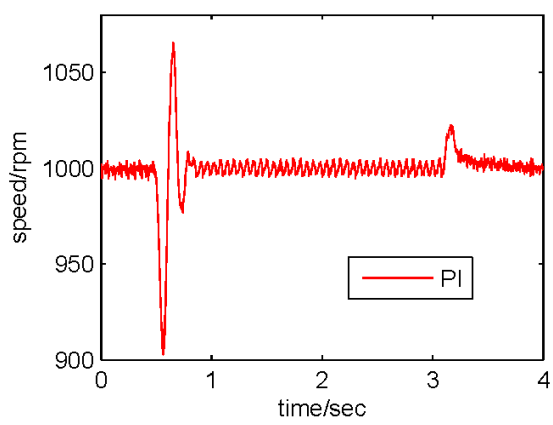

(a)

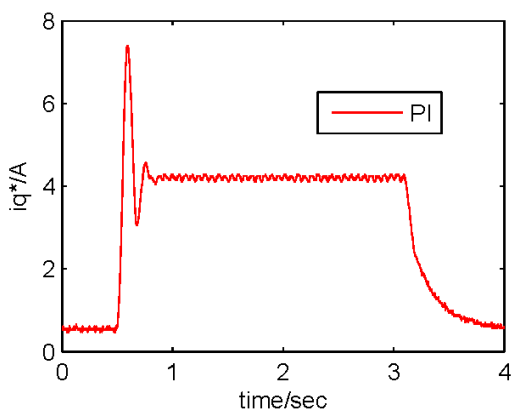

(b)

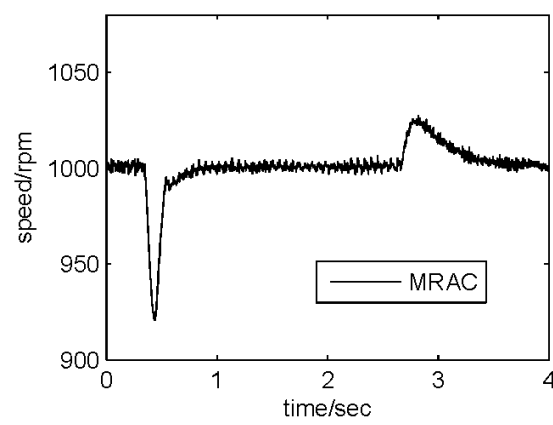

(c)

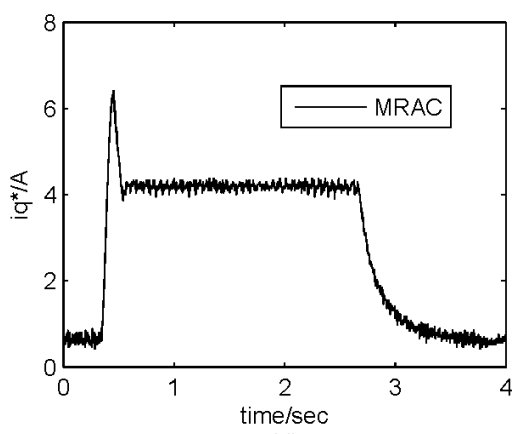

(d)

Fig. 13. Experimental response curves in the presence of a sudden load torque disturbance in the case of $1000 \mathrm{rpm}$ : (a) speed (PI). (b) $i_{q}^{*}$ (PI). (c) speed (MRAC). (d) $i_{q}^{*}$ (MRAC). 


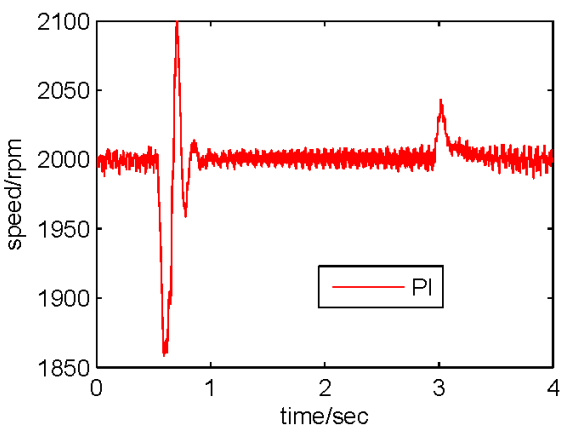

(a)

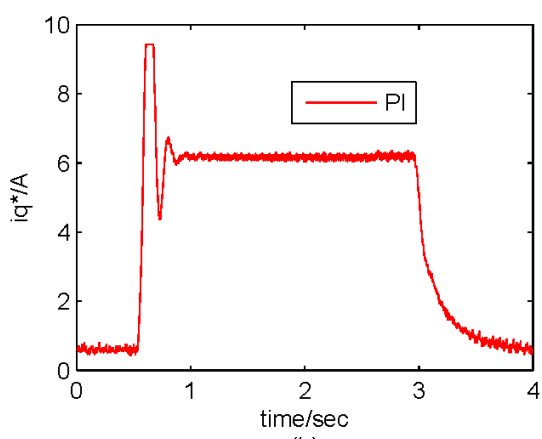

(b)

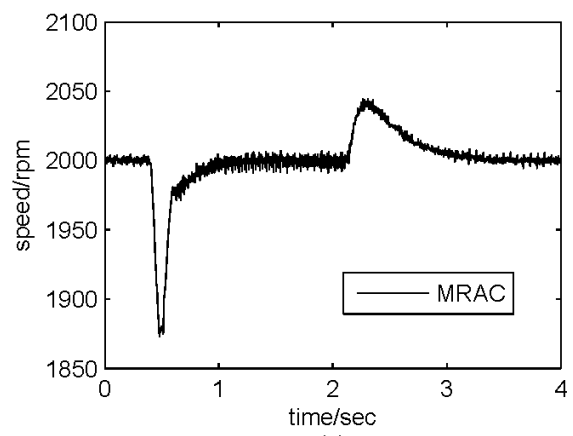

(c)

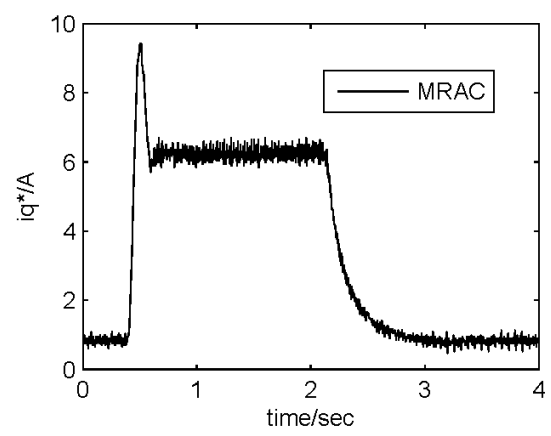

(d)

Fig. 14. Experimental response curves in the presence of a sudden load torque disturbance in the case of $2000 \mathrm{rpm}$ : (a) speed (PI). (b) $i_{q}^{*}$ (PI). (c) speed (MRAC). (d) $i_{q}^{*}$ (MRAC).

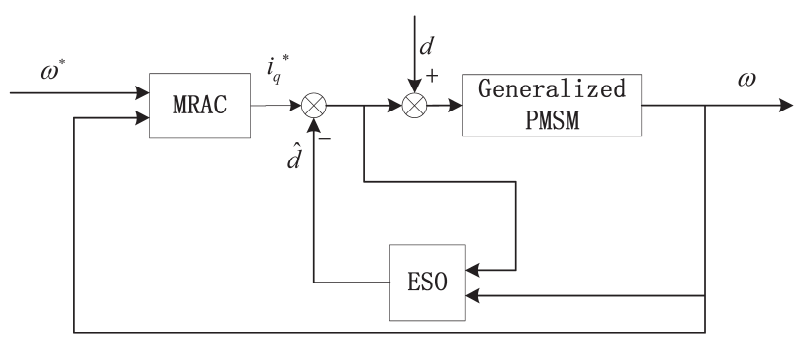

Fig. 15. The block diagram of MRAC+ESO method for PMSM system.

$$
\left\{\begin{array}{l}
\dot{x}_{1}=x_{2}-a x_{1}+b i q^{*} \\
\dot{x}_{2}=c(t)
\end{array}\right.
$$

where $c(t)$ is the derivative of $d(t)$.

Then, a second-order linear ESO for system (13) is designed as follows:

$$
\left\{\begin{array}{l}
\dot{z}_{1}=z_{2}-a x_{1}-2 p\left(z_{1}-x_{1}\right)+b i q^{*} \\
\dot{z}_{2}=-p^{2}\left(z_{1}-x_{1}\right)
\end{array}\right.
$$

where $z_{1}$ is the estimation of speed $x_{1}, z_{2}$ is the estimation of $x_{2}$, and $-p$ is the desired pole of the ESO with $p>0$.

The block diagram of the composite control method based on a MRAC and an ESO is shown in Fig. 15. It can be observed that a MRAC controller and an extended state observer are employed to construct the composite
MRAC+ESO structure. Under this control method, the composite control form is:

$$
u=i_{q}^{*}-\hat{d}(t)
$$

\section{B. Stability Analysis}

Assumption 1. The disturbance $d(t)$ is bounded, and it satisfies $\dot{d}(t)=0$.

$\underline{\text { Lemma } 1}$ [34]. Let V: $[0, \infty) \times R^{n} \rightarrow R$ be a continuously differentiable function such that:

$$
\alpha_{1}(\|x\|) \leq V(t, x) \leq \alpha_{2}(\|x\|)
$$

$$
\frac{\partial V}{\partial t}+\frac{\partial V}{\partial x} f(t, x, u) \leq-W_{3}(x), \forall\|x\| \geq \rho(\|u\|)>0
$$

$\forall(t, x, u) \in[0, \infty) \times R^{n} \times R^{m}$, where $\alpha_{1}$ and $\alpha_{2}$ are class $K_{\infty}$ functions, $\rho$ is a class $K$ function, and $W_{3}(x)$ is a continuous positive definite function of $R^{n}$. Then, the system $\dot{x}=f(t, x, u), x \in R^{n}, u \in R^{m}$ is input-to-state stable with $\gamma=\alpha_{1}^{-1} \circ \alpha_{2} \circ \rho$.

Lemma 2 [34]. If the following system:

$$
\dot{x}=f(t, x, u)
$$

satisfies the following conditions so that: 1 . system (16) is 


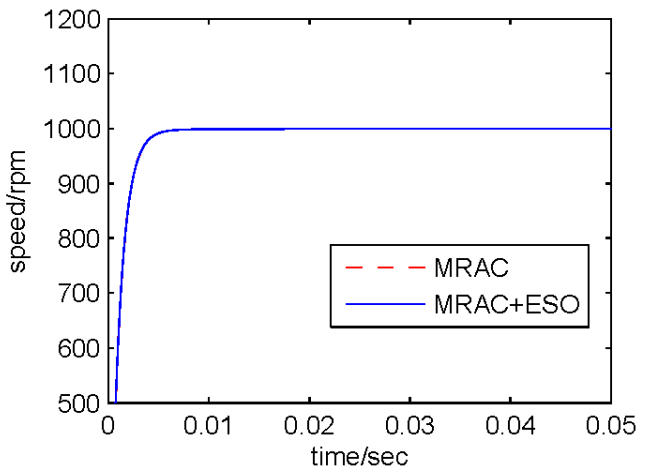

(a)

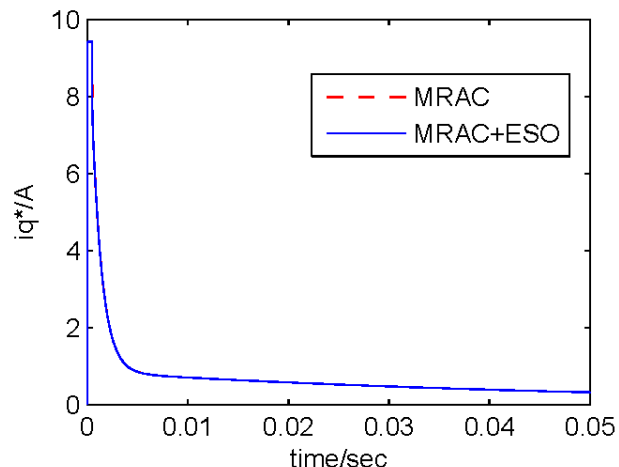

(b)

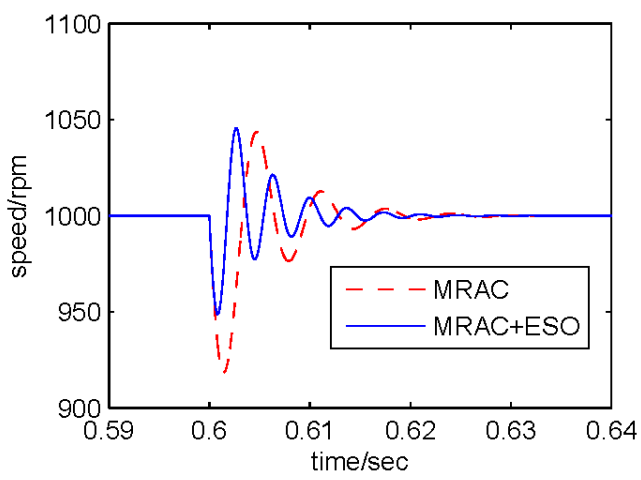

(c)

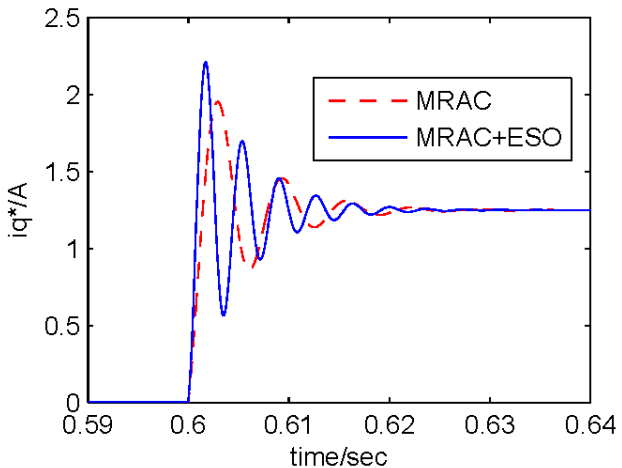

(d)

Fig. 16. Simulation response curves under MRAC+ESO and MRAC controllers: (a) speed. (b) $i_{q}{ }^{*}$. (c) speed response curves in the presence of load torque disturbance. (d) $i_{q}{ }^{*}$ response curves in the presence of load torque disturbance.

globally input-state stable; and 2. $\lim _{t \rightarrow \infty} u=0$, then the states of system (16) are asymptotically convergent to zero.

By substituting (15) into (2) and combining with (3), the speed tracking error is given by:

$$
\begin{aligned}
\dot{e} & =-a_{m} \omega_{m}+b_{m} \omega^{*}+a \omega-b h(t) \omega-b k(t) \omega \\
& -b[d(t)-\hat{d}(t)] \\
& =-a_{m} e+b \phi^{T}\left[\omega^{*} \omega\right]^{T}-b[d(t)-\hat{d}(t)]
\end{aligned}
$$

For system (17), choose the Lyapunov function as:

$$
V=\frac{1}{2} e^{2}+\frac{b}{2} \phi^{T}\left[\begin{array}{ll}
\gamma_{1} & \\
& \gamma_{2}
\end{array}\right] \phi
$$

where $\gamma_{1}>0, \gamma_{2}>0$.

The differentiation of (18) along the trajectory of (17) yields:

$$
\dot{V}=-a_{m} e^{2}-b e[d(t)-\hat{d}(t)]-b\|\phi\|^{2}
$$

1) If $b \geq a_{m}$, then (19) can be written as:

$$
\begin{aligned}
& \dot{V} \leq-\frac{a_{m}}{2}\left(|e|^{2}+\|\phi\|^{2}\right)-\frac{a_{m}}{2}\left(|e|^{2}+\|\phi\|^{2}\right) \\
& -\left(b-a_{m}\right)\|\phi\|^{2}+b\left(|e|^{2}+\|\phi\|^{2}\right)^{\frac{1}{2}}|d(t)-\hat{d}(t)|
\end{aligned}
$$

Supposing that:

$$
-\frac{a_{m}}{2}\left(|e|^{2}+\|\phi\|^{2}\right)+b\left(|e|^{2}+\|\phi\|^{2}\right)^{\frac{1}{2}}|d(t)-\hat{d}(t)| \leq 0
$$

That is to say:

$$
\left(|e|^{2}+\|\phi\|^{2}\right)^{\frac{1}{2}} \geq \frac{2 b|d(t)-\hat{d}(t)|}{a_{m}}
$$

In this case, it can be seen that:

$$
\begin{aligned}
\dot{V} & \leq-\frac{a_{m}}{2}\left(|e|^{2}+\|\phi\|^{2}\right)-\left(b-a_{m}\right)\|\phi\|^{2} \\
& =-\frac{a_{m}}{2}|e|^{2}-\left(b-\frac{a_{m}}{2}\right)\|\phi\|^{2} \leq 0
\end{aligned}
$$

2) If $b<a_{m}$, then (19) can also be written as:

$$
\begin{aligned}
& \dot{V} \leq-\frac{b}{2}\left(|e|^{2}+\|\phi\|^{2}\right)-\frac{b}{2}\left(|e|^{2}+\|\phi\|^{2}\right) \\
& -\left(a_{m}-b\right)|e|^{2}+b\left(|e|^{2}+\|\phi\|^{2}\right)^{\frac{1}{2}}|d(t)-\hat{d}(t)|
\end{aligned}
$$

Supposing that:

$$
-\frac{b}{2}\left(|e|^{2}+\|\phi\|^{2}\right)+b\left(|e|^{2}+\|\phi\|^{2}\right)^{\frac{1}{2}}|d(t)-\hat{d}(t)| \leq 0
$$

That is to say:

$$
\left(|e|^{2}+\|\phi\|^{2}\right)^{\frac{1}{2}} \geq 2|d(t)-\hat{d}(t)|
$$




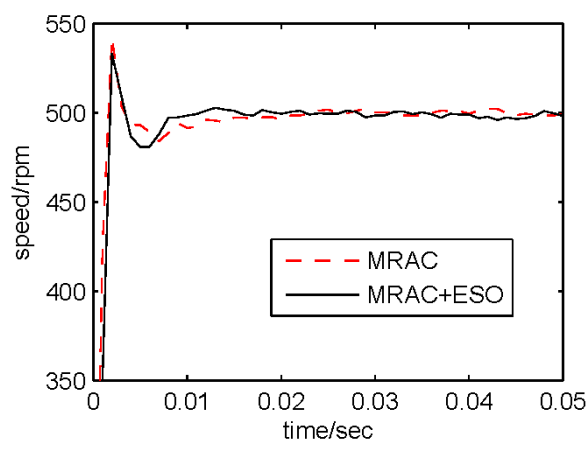

(a)

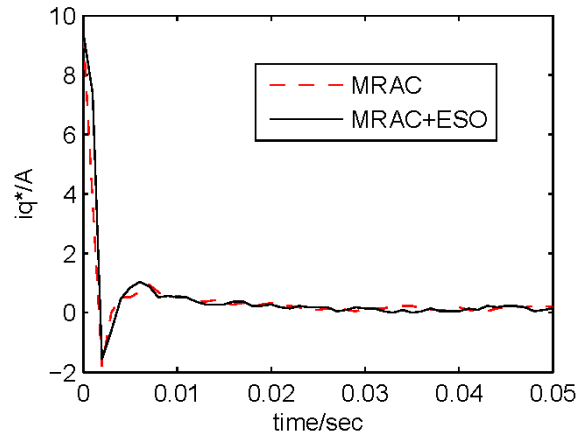

(b)

Fig. 17. Experimental response curves when the reference speed is $500 \mathrm{rpm}$ : (a) speed and (b) $i_{q}{ }^{*}$.

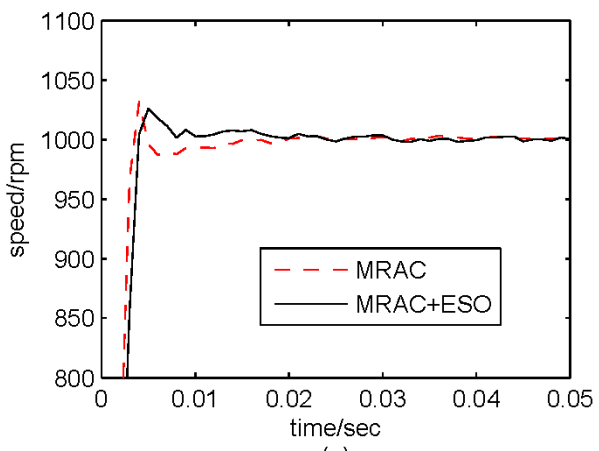

(a)

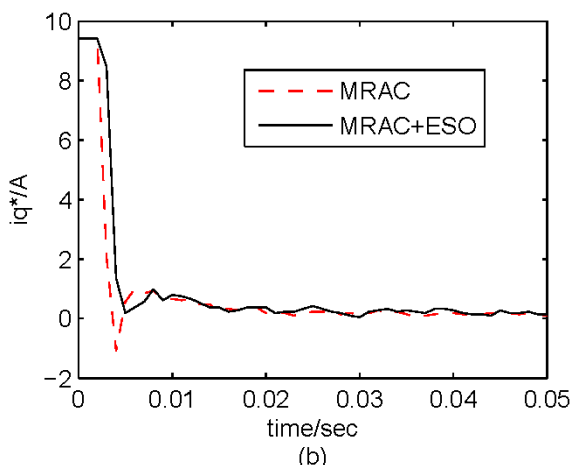

(b)

Fig. 18. Experimental response curves when the reference speed is $1000 \mathrm{rpm}$ : (a) speed and (b) $i_{q}{ }^{*}$.

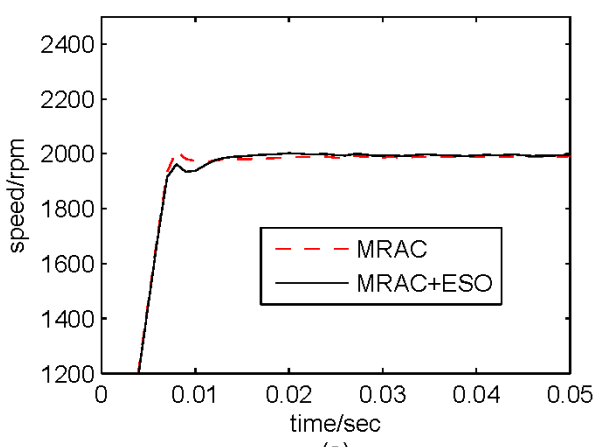

(a)

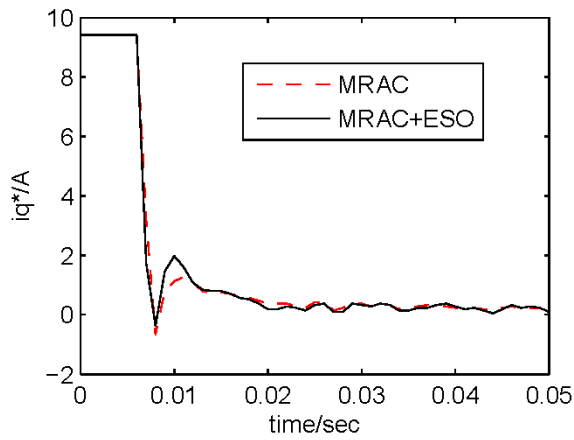

(b)

Fig. 19. Experimental response curves when the reference speed is $2000 \mathrm{rpm}$ : (a) speed and (b) $i_{q}{ }^{*}$.

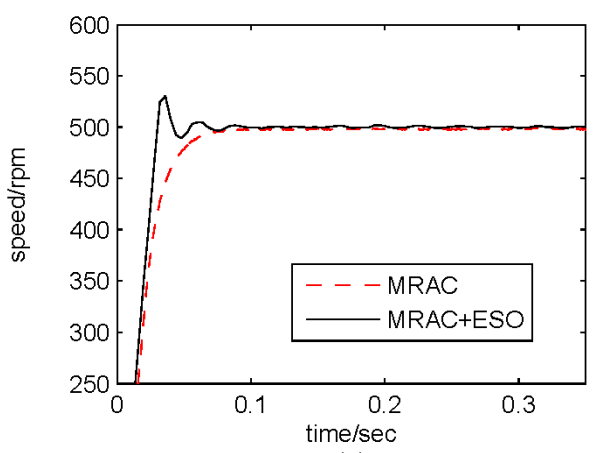

(a)

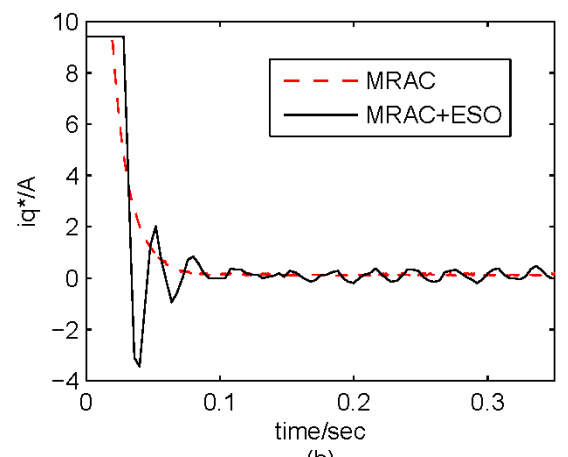

(b)

Fig. 20. Experimental response curves when $J$ is increased to $11 \mathrm{~J}$ and reference speed is $500 \mathrm{rpm}$ : (a) speed and (b) $i_{q}{ }^{*}$. 
Then it can be seen that:

$$
\begin{aligned}
\dot{V} & \leq-\frac{b}{2}\left(|e|^{2}+\|\phi\|^{2}\right)-\left(a_{m}-b\right)|e|^{2} \\
& =-\frac{b}{2}\|\phi\|^{2}-\left(a_{m}-\frac{b}{2}\right)|e|^{2} \leq 0
\end{aligned}
$$

From the above analysis for both cases, by Lemma 1 it can be seen that system (17) is input-state stable.

Consider the situations where the lumped disturbances $d(t)$ satisfy Assumption 1. According to the analysis in [33], the ESO states $z_{1}(t) \rightarrow x_{1}(t)$ and $z_{2}(t) \rightarrow x_{2}(t)$. Then the estimation of the disturbance $\hat{d}(t)=z_{2}(t)$ satisfies:

$$
\lim _{t \rightarrow \infty}[d(t)-\hat{d}(t)]=0
$$

Treat $|d(t)-\hat{d}(t)|$ as the system input and together with (28) and Lemma 2, it can be concluded that the closed loop system is asymptotically stable.

\section{Simulation and Experimental Results}

To evaluate the performance of the proposed composite method, simulations and experiments on the PMSM system also have been performed.

Simulation Results: The parameters for the MRAC+ESO speed controller are: $a_{m}=b_{m}=100, \gamma_{1}=\gamma_{2}=0.015$ and $p=450$. The speed response curves under the MRAC+ESO are shown in Fig. 16. From the curves, it can be seen that the MRAC and MRAC+ESO methods have almost the same speed response without a load torque disturbance. However, when a sudden load torque disturbance $T_{L}=2 N \cdot m$ applied at $t=0.6 s$, it can be seen that the system using the $\mathrm{MRAC}+\mathrm{ESO}$ controller provides less speed fluctuation against disturbance.

Experimental Results: In the experiments, the MRAC+ESO parameters of the speed-loop are selected as: $a_{m}=b_{m}=100$, $\gamma_{1}=\gamma_{2}=1$ and $p=250$. The speed responses under the MRAC+ESO method are shown in Figs. 17, 18 and 19 when the reference speed is given as $500 \mathrm{rpm}, 1000 \mathrm{rpm}$ and 2000 rpm, respectively. From the response curves, the MRAC and MRAC+ESO methods have almost the same speed response which corresponds to the simulation.

Then the inertia $J$ of the PMSM system is increased to $11 \mathrm{~J}$. Experiments are then performed to test the adaptability of the MRAC+ESO method. The results are shown in Figs. 20, 21 and 22.

Tests have also been done to evaluate the disturbance rejection ability of the MRAC+ESO method in the presence of sudden load torque disturbances. The results are shown in Figs. 23, 24 and 25. When compared with the MRAC method, the proposed MRAC+ESO method has a smaller speed decrease

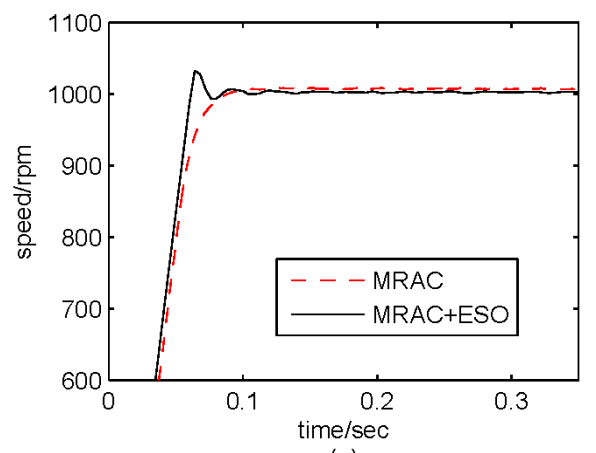

(a)

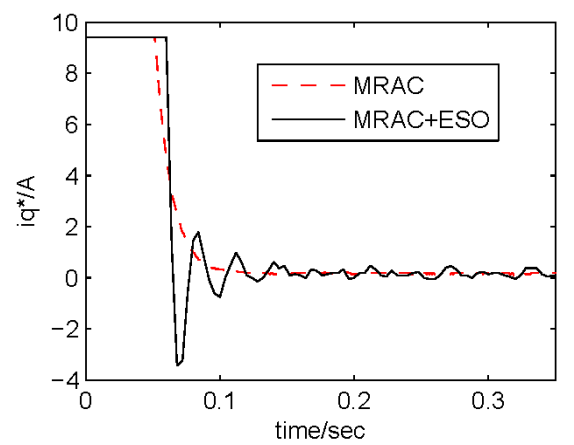

(b)

Fig. 21. Experimental response curves when $J$ is increased to $11 \mathrm{~J}$ and reference speed is $1000 \mathrm{rpm}$ : (a) speed and (b) $i_{q}{ }^{*}$.

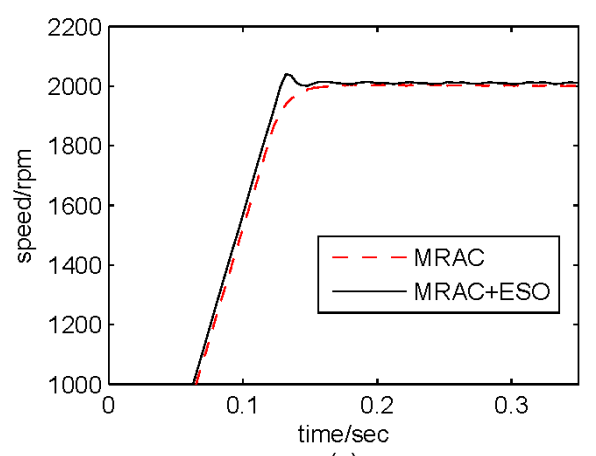

(a)

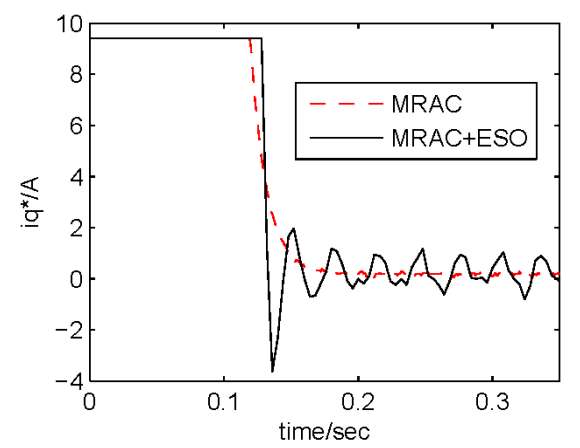

(b)

Fig. 22. Experimental response curves when $J$ is increased to $11 J$ and reference speed is $2000 \mathrm{rpm}$ : (a) speed and (b) $i_{q}{ }^{*}$. 


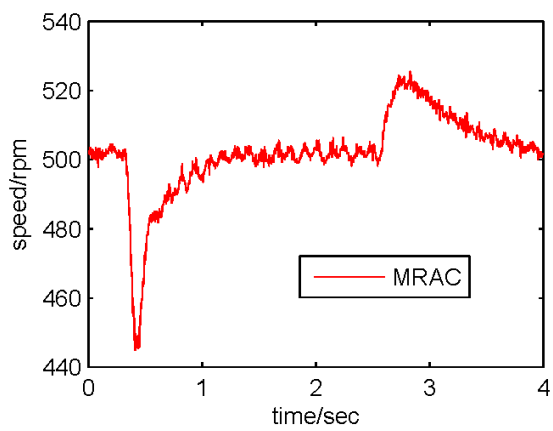

(a)

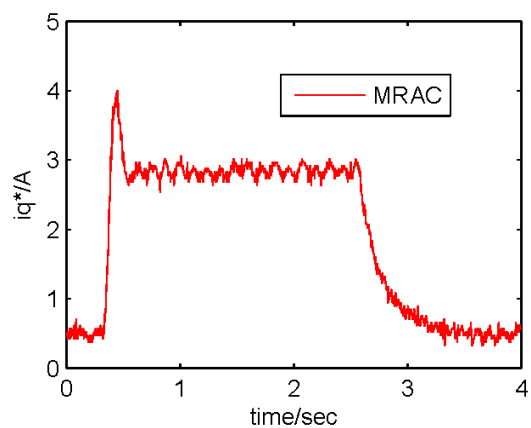

(b)

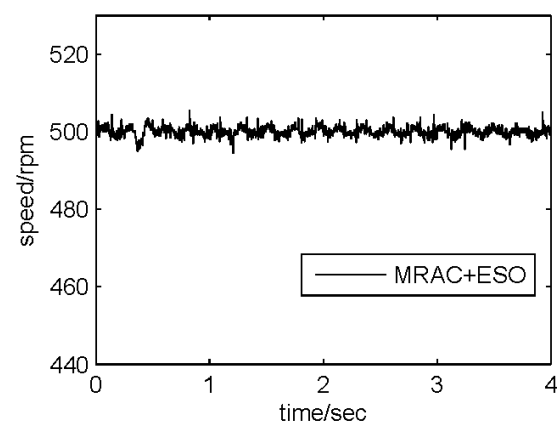

(c)

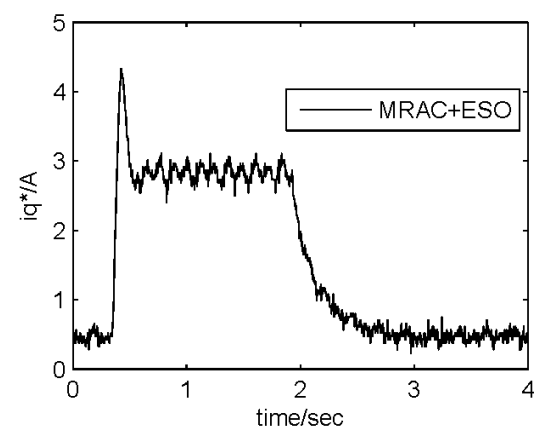

(d)

Fig. 23. Experimental response curves in the presence of sudden load torque disturbance in the case of 500 rpm: (a) speed (MRAC). (b) $i_{q}^{*}$ (MRAC). (c) speed (MRAC+ESO). (d) $i_{q}^{*}$ (MRAC+ESO).

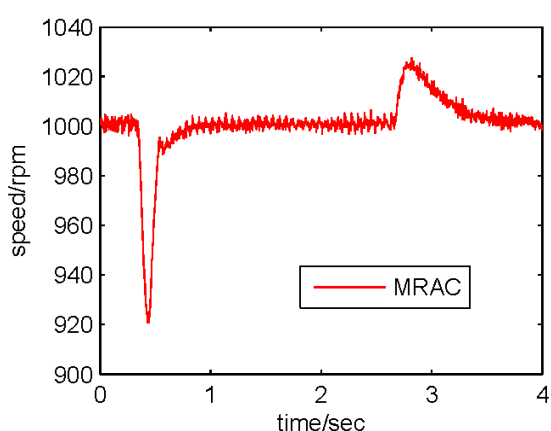

(a)

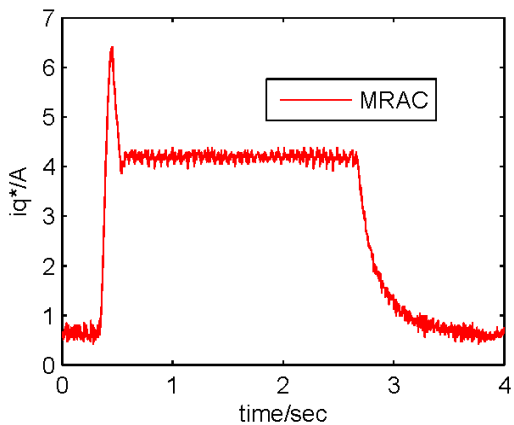

(b)

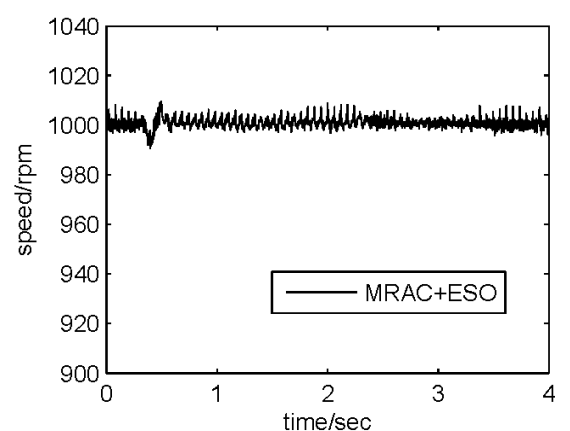

(c)

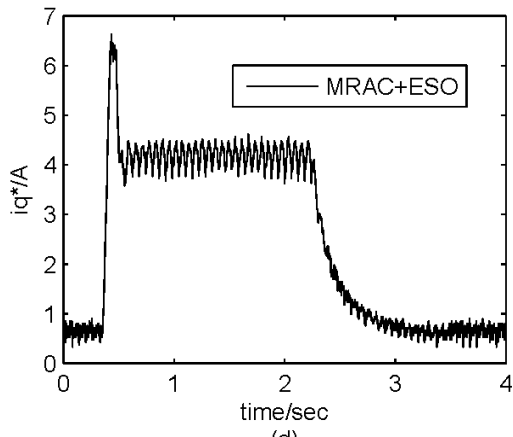

(d)

Fig. 24. Experimental response curves in the presence of sudden load torque disturbance in the case of $1000 \mathrm{rpm}$ : (a) speed (MRAC). (b) $i_{q}^{*}$ (MRAC). (c) speed (MRAC+ESO). (d) $i_{q}^{*}$ (MRAC+ESO). 


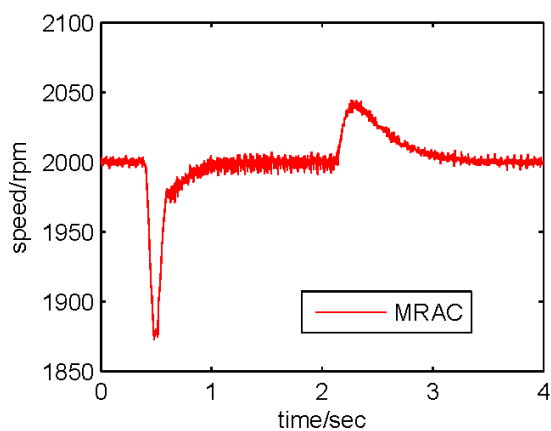

(a)

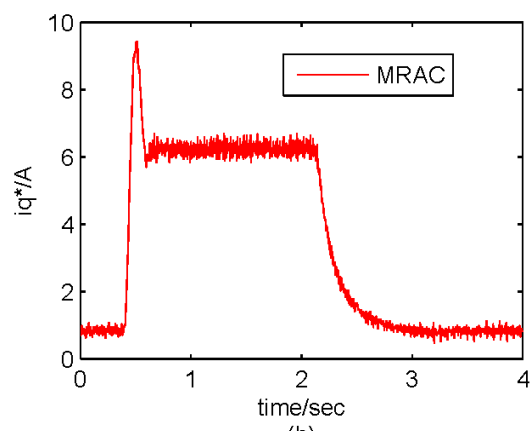

(b)

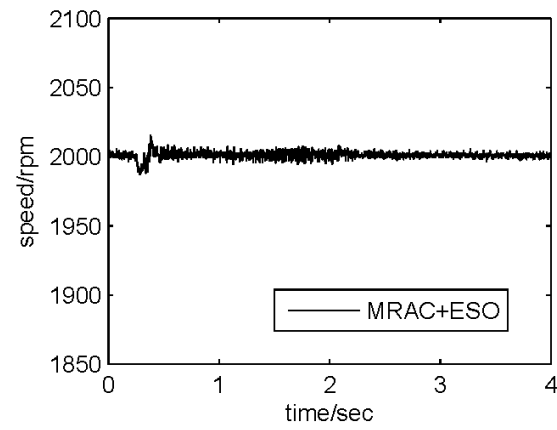

(c)

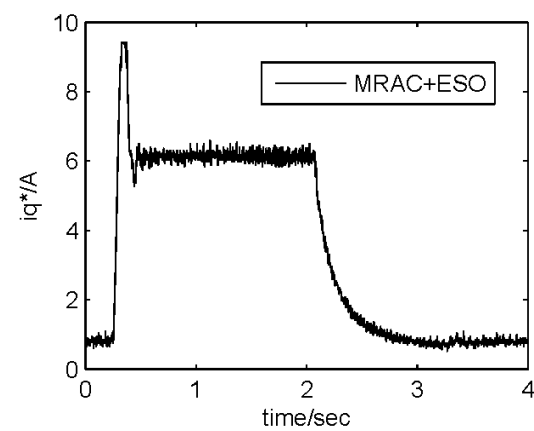

(d)

Fig. 25. Experimental response curves in the presence of sudden load torque disturbance in the case of $2000 \mathrm{rpm}$ : (a) speed (MRAC). (b) $i_{q}^{*}$ (MRAC). (c) speed (MRAC+ESO). (d) $i_{q}^{*}$ (MRAC+ESO).

TABLE II

PERFORMANCE INDEXES

\begin{tabular}{|c|c|c|c|c|c|}
\hline $\begin{array}{c}\text { Reference speed } \\
(\mathrm{rpm})\end{array}$ & $\begin{array}{c}\text { Control } \\
\text { algorithm }\end{array}$ & $\begin{array}{c}\text { Overshoot } \\
(\%)\end{array}$ & $\begin{array}{c}\text { Settling time } \\
(\mathrm{ms})\end{array}$ & $\begin{array}{c}\text { Steady speed ripple } \\
(\mathrm{rpm})\end{array}$ & $\begin{array}{c}\text { Standard deviation of steady speed } \\
(\mathrm{rpm})\end{array}$ \\
\hline \multirow{3}{*}{500} & MRAC+ESO & 6.6500 & 3 & 4.0000 & 1.4325 \\
& MRAC & 7.4740 & 3 & 3.2500 & 1.1640 \\
& PI & 5.0000 & 2 & 5.6250 & 2.2756 \\
\hline \multirow{3}{*}{1000} & MRAC+ESO & 2.1100 & 4 & 3.7500 & 1.4708 \\
& MRAC & 2.9700 & 4 & 3.3750 & 1.1531 \\
& PI & 8.2500 & 20 & 4.7500 & 2.0406 \\
\hline \multirow{3}{*}{2000} & MRAC+ESO & 0.1125 & 7 & 5.1250 & 1.9418 \\
& MRAC & 0.6000 & 7 & 4.5000 & 1.6018 \\
& PI & 16.6125 & 28 & 4.2500 & 1.6781 \\
\hline
\end{tabular}

and a shorter recovery time while maintaining a good dynamic performance.

From all of the experimental results above, it can be seen that although the MRAC+ESO method degrades the adaptation ability, it can obtain a better tracking performance and disturbance rejection when compared to the PI and MRAC methods.

The performance indexes of each control method under different conditions are shown in Table II.

\section{CONCLUSIONS}

In this paper, the design of a speed controller based on the MRAC for the PMSM has been investigated. This method has shown a better adaptation ability when compared with the PI method. In order to improve the disturbance rejection ability of the controller, a composite controller which combines the MRAC method with an ESO has been proposed. Simulation and experimental results validate that the composite method can obtain a satisfying performance with a faster transient response and a better disturbance rejection capability.

\section{ACKNOWLEDGMENTS}

This work was supported by New Century Excellent Talents in University (NCET-10-0328), Science Foundation for Distinguished Young Scholars of Jiangsu Province under Grant BK20130018 and High-level Talents Program in Six Industries of Jiangsu Province under Grant DZXX-30. 


\section{REFERENCES}

[1] G. J. Wang, C. T. Fong, and K. J. Chang, "Neural-network-based self-tuning PI controller for precise motion control of PMAC motors," IEEE Trans. Ind. Electron., Vol. 48, No. 2, pp. 408-415, Apr. 2001.

[2] R. L. A. Ribeiro, A. D. Araujo, A. C. Oliveria, and C. B. Jacobina, "A high performance permanent magnet synchronous motor drive by using a robust adaptive control strategy," Power Electroics Specialists Conference, pp. 2260-2266, 2007.

[3] S. H. Li and Z. G. Liu, "Adaptive speed control for permanent-magnet synchronous motor system with variations of load inertia," IEEE Trans. Ind. Electron., Vol. 56, No. 8, pp. 3050-3059, Aug. 2009.

[4] H. H. Choi, N. T.-T. Vu, and J.-W. Jung, "Digital implementation of an adaptive speed regulator for a PMSM," IEEE Trans. Power Electron., Vol. 26, No. 1, pp. 3-8, Jan. 2011.

[5] T.-H. Liu, H.-T. Pu, and C.-K. Lin, "Implementation of an adaptive position control system of a permanent-magnet synchronous motor and its application," IET Electric Power Applications, Vol. 4, No. 2, pp. 121-130, Feb. 2010.

[6] K.-H. Kim, "Model reference adaptive control-based adaptive current control scheme of a PM synchronous motor with an improved servo performance," IET Electric Power Applications, Vol. 3, No. 1, pp. 8-18, Jan. 2009.

[7] W.-H. Chen, "Disturbance observer based control for nonlinear system," IEEE/ASME Trans. Mechatron., Vol. 9, No. 4, pp. 706-710, Dec. 2004.

[8] S. E. Talole, J. P. Kolhe, and S. B. Padke, "Extended-state-observer-based control of flexible-joint system with experimental validation," IEEE Trans. Ind. Electron., Vol. 57, No. 4, pp. 1411-1419, Apr. 2010.

[9] C. K. Lai and K. K. Shyu, "A novel motor drive design for incremental motion system via sliding-mode control method," IEEE Trans. Ind. Electron., Vol. 52, No. 2, pp. 499-507, Apr. 2005.

[10] S. H. Li, M. M. Zhou, and X. H. Yu, "Design and implementation of terminal slide mode control method for PMSM speed regulation system," IEEE Trans. Ind. Informat., Vol. 3, No. 99, pp. 1-11, Nov. 2012.

[11] K. Jezernik, J. Korelic, and R. Horvat, "PMSM slide mode FPGA-based control for torque ripple reduction," IEEE Trans. Power Electron., Vol. 28, No. 7, pp. 3549-3556, Jul. 2013.

[12] F. M. S. Fayez, "Robust adaptive wavelet-neural-network sliding-mode speed control for a DSP-based PMSM drive system," Journal of Power Electronics, Vol. 10, No. 5, pp. 505-517, Jul. 2010.

[13] P. H. Cortes, M. P. Kazmierkowski, R. M. Kennel, D. E. Quevedo, and J. Rodriguez, "Predictive control in power electronics and drive," IEEE Trans. Ind. Electron., Vol. 55, No. 12, pp. 4312-4324, Dec. 2008.

[14] R. Errouissi, M. Ouhrouche, W.-H. Chen, and A. M. Trzynadlowski, "Robust nonlinear predictive controller for a PMSM with optimized cost function," IEEE Trans. Ind. Electron., Vol. 59, No. 7, pp. 2849-2858, Jul. 2012.

[15] R. J. Wai, "Hybrid fuzzy neural network control for nonlinear motor-toggle servomechanism," IEEE Trans. Contr. Syst. Technol., Vol. 10, No. 4, pp. 519-532, Jul. 2002.

[16] F. J. Lin, T. S. Lee, and C. H. Lin, "Robust $H_{\infty}$ controller design with recurrent neural network for linear synchronous motor drive," IEEE Trans. Ind. Electron., Vol. 50, No. 3, pp. 456-470, Jun. 2003.

[17] S. H. Li and H. X. Liu, "A speed control for a PMSM using finite-time feedback and disturbance compensation," Transactions of the Institute of Measurement and Control, Vol. 32, No. 2, pp. 170-187, Apr. 2010

[18] A. V. Sant and K. R. Rajagopal, "PM synchronous motor speed control using hybrid fuzzy-PI," IEEE Trans. Magn., Vol. 45, No. 10, pp. 4672-4675, Oct. 2009.

[19] J.-W. Jung, H. H. Choi, and T.-H. Kim, "Fuzzy PD speed controller for permanent magnet synchronous motors," Journal of Power Electronics, Vol. 11, No. 6, pp. 819-823, May. 2011.

[20] J.-W. Jung, H. H. Choi, and D.-M. Lee, "Implementation of a robust fuzzy adaptive speed tracking control system for permanent magnet synchronous motors," Journal of Power Electronics, Vol. 12, No. 6, pp. 904-911, Nov. 2012.

[21] I. D. Landau, "A survey of model reference adaptive techniques-theory and applications," Automatica, Vol. 10, No. 4, pp. 353-379, Jun. 1974.

[22] F. Alonge and F. M. Raimondi, "Model reference adaptive control of motion control system with induction motor," IEEE International Symposium on Ind. Electronics, pp. 803-808, 1995 .

[23] N. Golea, A. Golea, and M. Kadjoudj, "Robust MRAC adaptive control of PMSM drive under general parameters uncertainties," IEEE International Conference on Ind. Technology, pp. 767-771, 2006.

[24] Y. Sozer, H. Kaufman, and D. A.Torrey, "Direct model reference adaptive control of permanent magnet brushless DC motor," IEEE International Conference on Control Applications, pp. 633-638, 1997.

[25] A. S. Kumar, M. S. Rao, and Y. S. K. Babu, "Model reference linear adaptive control of DC motor using fuzzy controller," IEEE Region 10 Conference, pp. 1603-1607, 2008

[26] N. Leena and R. Shanmugasundaram, "Adaptive controller for improved performance of brushless DC motor," IEEE International Conference on Data Science and Engineering, pp. 117-122, 2012.

[27] A. F. A. Furtunato, "A robust control for induction motor using a variable structure model reference adaptive control (VS-MRAC)," IEEE International Power electronics Congress, pp. 61-69, 1998

[28] H. X. Liu and S. H. Li, "Speed control for PMSM servo system using predictive functional control and extended state observer," IEEE Trans. Ind. Electron., Vol. 59, No. 2, pp. 1171-1183, Feb. 2012.

[29] S. H. Li, C. J. Xia, and X. Zhou, "Disturbance rejection control method for permanent magnet synchronous motor speed-regulation system," Mechatronics, Vol. 22, No. 6, pp. 706-714, Sep. 2012.

[30] P. C. Krause, Analysis of Electric Machinery, New Jersey: McGraw-Hill, Chap. 4, 1995.

[31] J. Q. Han, "The extended states observer of a class of uncertain systems," Control Decision, Vol. 10, No. 1, pp. 85-88, Jan. 1995. (in Chinese)

[32] J. Q. Han, "From PID to active disturbance rejection control," IEEE Trans. Ind. Electron., Vol. 56, No. 3, pp. 900-906, Mar. 2009.

[33] R. Miklosovic and Z. Q. Gao, "A robust two-degree-of-fredom control design technique and its practical application," IEEE Industry Applications Conference, pp. 1495-1502, 2004. 
[34] H. K. Khalil. Nonlinear Systems, Prentice-Hall, Chap. 4, 2002.

[35] H. B. Sun, S. H. Li, and S. M. Fei, "A composite control scheme for 6DOF spacecraft formation control," Acta Astronautica, Vol. 69, No. 7-8, pp. 595-611, Sep. 2011.

[36] J. Su, W. Qiu, H. Ma, and P.-Y. Woo, "Calibration-free robotic eye-hand coordination based on an auto disturbance-rejection controller," IEEE Trans. Robot., Vol. 20, No. 5, pp. 899-907, Oct. 2004.

[37] D. Sun, "Comments on active disturbance rejection control," IEEE Trans. Ind. Electron., Vol. 54, No. 6, pp. 3428-3429, Dec. 2007.

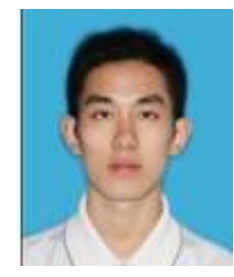

Xiaodi Li was born in Wuhu, China, in 1989. $\mathrm{He}$ received his B.S. degree in Automatic Control from Hohai University, Nanjing, China, in 2011, and his M.S. degree in Automatic Control from Southeast University, Nanjing, China, in 2014. His current research interests include control theory and its application to motor systems.

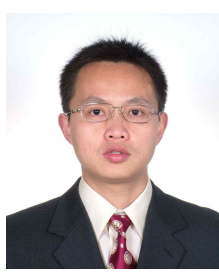

Shihua Li was born in Pingxiang, China, in 1975. He received his B.S., M.S. and Ph.D. degrees all in Automatic Control from Southeast University, Nanjing, China, in 1995, 1998 and 2001, respectively. Since 2001, he has been with the School of Automation, Southeast University, where he is presently working as a Professor. His main research interests include nonlinear control theory and its application to robots, spacecrafts, AC motors and other mechanical systems. 